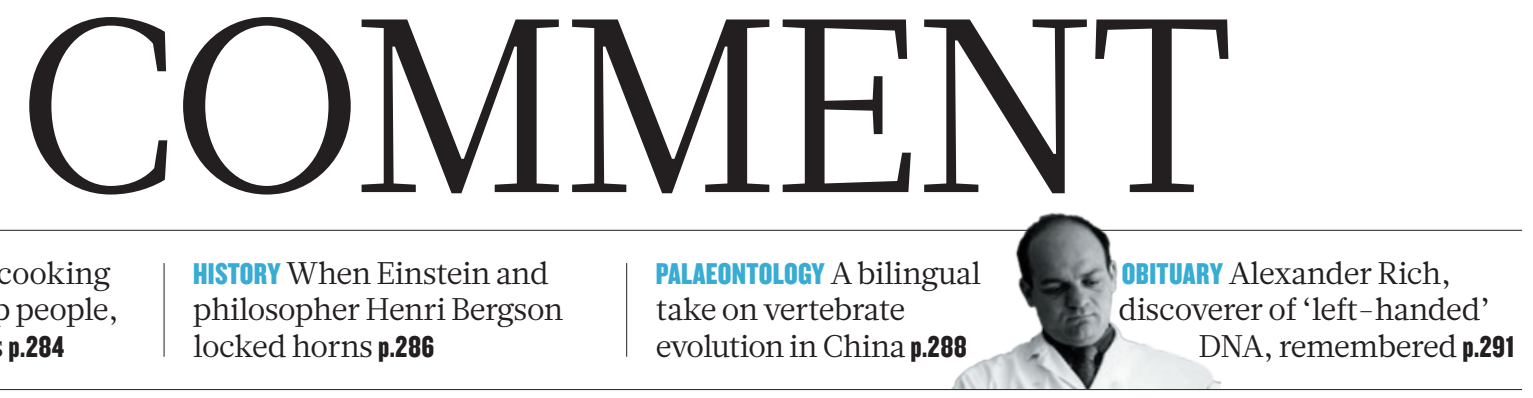

SUSTAINABILITY Clean-cooking initiatives must help people, not just swap stoves p.284 philosopher Henri Bergson

locked horns p.286
PALAEONTOLOGY A bilingual evolution in China p.288 DNA, remembered $\mathbf{p . 2 9}$

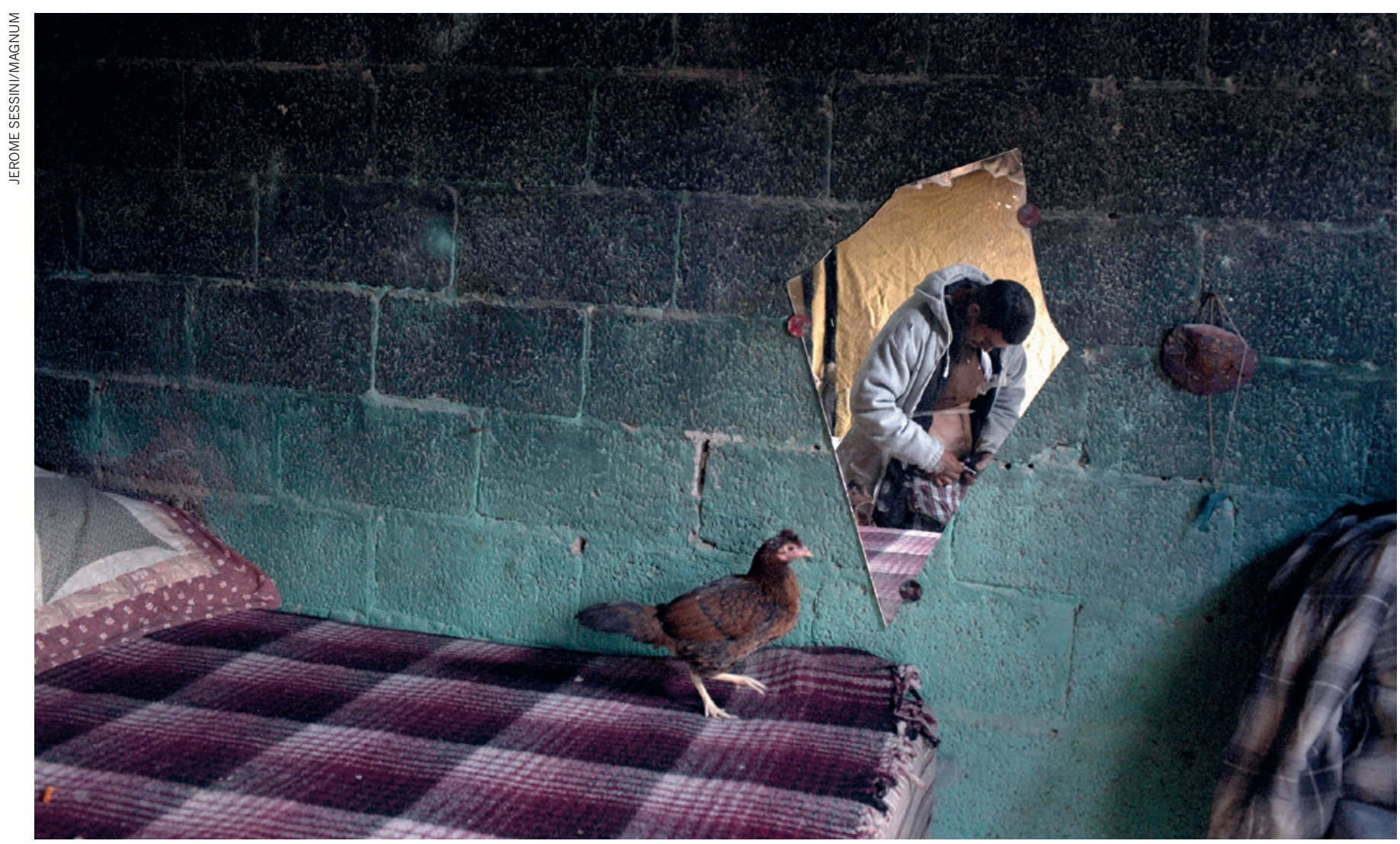

Illegal use of opiates such as heroin and morphine affects more than 16 million people worldwide.

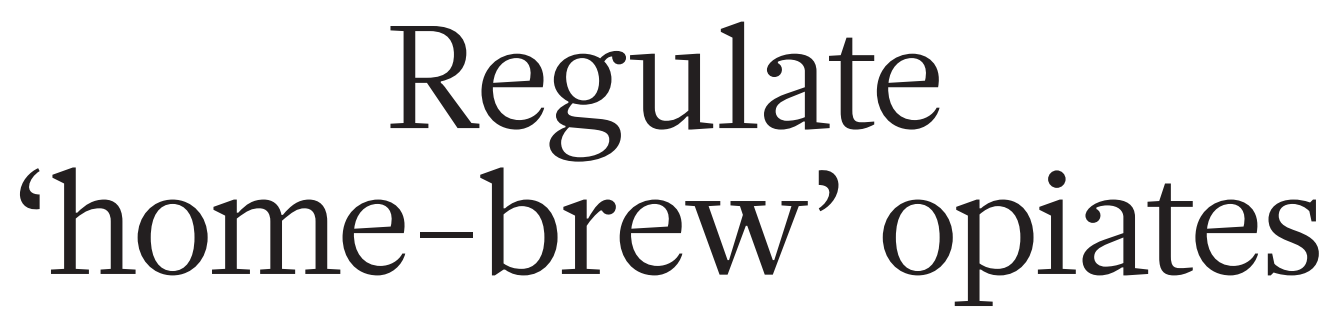

The research community and the public require a fast, flexible response to the synthesis of morphine by engineered yeasts, urge Kenneth Oye, Tania Bubela and J. Chappell H. Lawson.

$\mathrm{E}$ very year, thousands of students from across the world compete to build biological systems from preexisting parts in a competition organized by the International Genetically Engineered Machine (iGEM) Foundation. Last November, to spark discussion on security and health risks raised by synthetic biology,
FBI Special Agent Edward You presented an example: the production of opiates from sugar by yeast (Saccharomyces cerevisiae) that has been genetically modified.

You's hypothetical scenario is becoming a reality. One week after the iGEM competition, two developers of opiate-producing yeast strains approached us, specialists in biotechnology policy. They had results in advance of publication, and requested advice on how they might maximize the benefits of their research while mitigating the risks. Now, published papers by these researchers - John Dueber at the University of California, Berkeley, and his colleagues ${ }^{1}$, and Vincent Martin $>$ 


\section{BREWING BAD}

Researchers have completed all the steps of an engineered pathway in yeast that make the controlled substances thebaine and morphine from glucose.
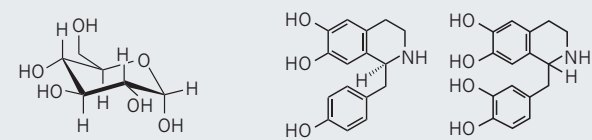

Glucose
Norcoclaurine or norlaudanosoline

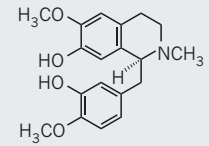

(S)-reticuline

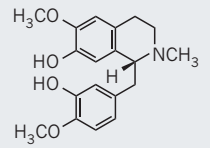

(R)-reticuline

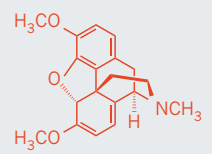

Thebaine

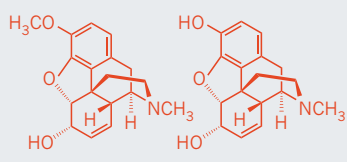

$>$

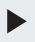

Codeine or morphine

Step completed 2008 (refs 5,6)

2015 (ref. 1)

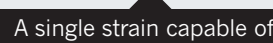

have difficulty controlling the distribution of an opiate-producing yeast strain. All told, decentralized and localized production would almost certainly reduce the cost and increase the availability of illegal opiates substantially worsening a worldwide problem. Globally, more than 16 million people use opiates illegally.

\section{FOUR RECOMMENDATIONS}

There are two major challenges to developing and implementing a flexible and proportionate regulatory approach for this research. Current regulations for engineered organisms focus on pathogenic organisms such as the anthrax bacterium and smallpox, not on yeasts. And the array of national and international drug regulators and lawenforcement agencies that would need to be involved have different practices and norms.

Increased communication and coordination will be required among publichealth experts, scientists, regulators and law-enforcement agencies. Potential international focal points for dialogue are the INCB and the international expert groups on biosafety and biosecurity regulation.

The following four issues warrant immediate consideration.

Engineering. Yeast strains should be designed to make them less appealing to criminals. For example, strains could be engineered to make only opiates with limited street value, such as thebaine. Alternatively, weaker strains could be engineered to make it harder for people to cultivate and harvest opiates outside established laboratory settings. Strains could be engineered with unusual nutrient dependencies, for instance. Such methods of 'biocontainment' have been developed in Escherichia coli. Opiate-producing yeast strains could also contain a marker, such as a DNA watermark, that makes them more readily identifiable to law-enforcement agencies.

Screening. Because there is some - albeit low - risk of criminal syndicates synthesizing opiate-producing yeast strains using published DNA sequences, commercial organizations that make stretches of DNA to order should be alerted. The sequences for opiate-producing yeast strains should be added to the screening criteria used by these providers. Overseen by two voluntary consortia, the International Association of Synthetic Biology and the International Gene Synthesis Consortium, these criteria currently cover only pathogens.

Security. Efforts should be made to keep opiate-producing yeast strains in controlled environments that are licensed by regulators. Physical biosecurity measures — including locks, alarms and systems for monitoring the use of laboratories and materials - could help to prevent the theft of yeast samples. Laboratory personnel should be subject to security screening. Similarly, assigning liability and penalties may dissuade researchers from sharing strains with anyone who is not legally authorized to work with them.

Regulation. The current laws covering opiates, such as the US Controlled Substance Act and its worldwide equivalents, should be extended to cover opiate-producing yeast strains, to make their release and distribution illegal.

The right choices in the regulation of this dual-use technology will set a precedent for other fast-emerging biotechnologies. In fact, biologists working on yeast-based opiates have already led the way on the most important aspect - namely, their willingness to take responsibility for the tools they are developing. But for them, this article would not have been written.

Other genomic engineers are following this path. Developers of the gene-editing tool CRISPR/Cas9 have called for proactive engagement with risks before altering populations of animals and plants in the wild or manipulating human reproductive cells $s^{9,10}$. With all the signs that synthetic biology is coming of age, this type of responsible conduct is imperative. $\mathrm{NEENEWS} \mathrm{P.267}$

Kenneth A. Oye and J. Chappell H. Lawson are associate professors in the Department of Political Science, Massachusetts Institute of Technology, Cambridge, Massachusetts, USA. Tania Bubela is professor and associate dean for research at the School of Public Health, University of Alberta, Edmonton, Canada. e-mail: oye@mit.edu

1. DeLoache, W. C. et al. Nature Chem. Biol. http:// dx.doi.org/10.1038/nchembio.1816 (2015).

2. Fossati, E., Narcross, L., Ekins, A., Falgueyret, J. P. \& Martin, V. J. J. PLOS ONE 10, e0124459 (2015)

3. Beaudoin, G. A. W. Characterization of Oxidative Enzymes Involved in the Biosynthesis of Benzylisoquinoline Alkaloids in Opium Poppy (Papaver somniferum). PhD thesis, Univ. Calgary (2015); available at http://hdl.handle. net/11023/2115

4. Bubela, T., Hagen, G. \& Einsiedel, E. Trends Biotechnol. 30, 132-137 (2012).

5. Hawkins, K. M. \& Smolke, C. D. Nature Chem. Biol. 4, 564-573 (2008).

6. Fossati, E. et al. Nature Commun. 5, 3283 (2014).

7. Thodey, K., Galanie, S. \& Smolke, C. D. Nature Chem. Biol. 10, 837-844 (2014).

8. International Narcotics Control Board. Report of the International Narcotics Control Board on the Availability of Internationally Controlled Drugs: Ensuring Adequate Access for Medical and Scientific Purposes (INCB, 2011).

9. Oye, K. A. et al. Science 345, 626-628 (2014). 10. Baltimore, D. et al. Science 348, 36-38 (2015). 